\title{
Intraoperative Vitamin C Reduces the Dosage of Propofol in Patients Undergoing Total Knee Replacement
}

\author{
Yang Li ${ }^{\prime}$ \\ Long Feng ${ }^{2}$ \\ Xiaoying Zhang' \\ Lianjun Huang' \\ Jie Song (D) \\ Guoqing Chen' \\ Yu Zhang ${ }^{3}$ \\ Chenggang Zhang ${ }^{4}$ \\ Weiguang $\mathrm{Li}^{4,5}$ \\ Zeguo Feng ${ }^{6}$
}

'First Medical Center, Chinese PLA General Hospital, Beijing, People's Republic of China; ${ }^{2}$ Department of Anesthesia, Hainan Hostipal of Chinese PLA General Hostipal, Beijing, People's Republic of China; ${ }^{3}$ Peking Union Medical College Hospital, Beijing, People's Republic of China; ${ }^{4}$ Beijing Institute of Radiation Medicine, State Key Laboratory of Proteomics, Cognitive and Mental Health Research Center, Beijing, People's Republic of China; ${ }^{5}$ Faculty of Psychology, Beijing Normal University, Beijing, People's Republic of China; ${ }^{6}$ Department of Pain Medicine, First Medical Center, Chinese PLA General Hospital, Beijing, People's Republic of China

Correspondence: Zeguo Feng First Medical Center, Chinese PLA General Hospital, Department of Pain Medicine, No. 28 Fuxing Road, Haidian District, Beijing, 100853, People's Republic of China

$\mathrm{Tel} / \mathrm{Fax}+86$ 0l 0-66938317

Email beijing_301@sina.com

Weiguang $\mathrm{Li}$

Beijing Institute of Radiation Medicine, State Key Laboratory of Proteomics, Cognitive and Mental Health Research Center, Beijing Normal University, No. 19 Xinjiekouwai St, Haidian District, Beijing, CN, I00875,

People's Republic of China

Tel +86 010-66930210

Email bnubrain.liwg@mail.bnu.edu.cn
Purpose: Propofol is commonly used as an intravenous anesthetic in surgical patients. However, its usage is associated with adverse effects. Auxiliary medication can reduce the dose of intravenous anesthetics. Hence, we investigated whether vitamin $\mathrm{C}$ could lower propofol dosage in elderly patients undergoing total knee replacement surgery.

Patients and Methods: The trial was carried out in PLA General Hospital in Beijing, China. We enrolled patients aged $\geq 50$ years who were undergoing unilateral total knee arthroplasty with total intravenous anesthesia combined with lumbar sciatic nerve block. The patients were randomly assigned to either the vitamin $\mathrm{C}(\mathrm{Vc})$ group $(0.067 \mathrm{~g} / \mathrm{kg})$ or the control group (an equivalent dose of normal saline). Nerve block was done for all the patients before the general anesthesia. The same depth of anesthesia was maintained during the operation. We compared the propofol dosage and adverse events (eg hypotension) during anesthesia between the two groups. This study was registered with the Chinese Clinical Trial Registry, www.chictr.org.cn, number ChiCTR-TRC-16010112.

Results: There were significant differences in the total infusion dose (Vc group: $704.3 \pm$ $188.6 \mathrm{mg}$; control group: $888.6 \pm 232.7 \mathrm{mg} ; p=0.016$ ) and the average maintenance dose of propofol (Vc group: $5.8 \pm 1.0 \mathrm{mg} / \mathrm{kg} / \mathrm{h}$; control group: $6.9 \pm 1.6 \mathrm{mg} / \mathrm{kg} / \mathrm{h} ; p=0.013$ ). But there were no significant differences in the induction dose of propofol (control group: $90 \mathrm{mg}$, range $80-115 \mathrm{mg}$; Vc group: $100 \mathrm{mg}$, range $90-110 \mathrm{mg}, p=0.379$ ) between the $\mathrm{Vc}$ and control groups. Furthermore, there were no significant differences in the hemodynamics and the incidence of intraoperative hypotension.

Conclusion: Vitamin C can reduce the dosage of propofol in patients undergoing total knee replacement.

Keywords: propofol, vitamin C, general anesthesia, elderly patients

\section{Introduction}

Propofol as an intravenous anesthetic has both anesthetic and antioxidant properties. ${ }^{1}$ Because of its fast onset and short induction effects, propofol is commonly used for surgical anesthesia in China. However, the most common side effect of the drug during induction is dose-dependent hypotension. Propofolrelated hypotension increases with increasing dosage, which is attributed to a decrease in the systemic vascular resistance and to a lesser extent to myocardial suppression. $^{2-7}$ The elderly patients are particularly sensitive to this effect. Reich et al reported that despite controlling for age, pre-existing hypotension, and physical conditions as defined by the American Society of Anesthesiologists (ASA), 
hypotension after induction was associated with increased mortality. ${ }^{8}$ Propofol also causes respiratory suppression and affects the regeneration of neurons, learning, and memory. ${ }^{9-11}$

Auxiliary medication can reduce the dosage of intravenous anesthetics and alleviate the adverse of anesthetics during the perioperation. ${ }^{12-14}$ For example, midazolam, narcotic analgesics, $\alpha 2$-receptor agonists, $\beta$-receptor blockers, and melatonin use with propofol can alleviate the postoperative adverse reactions and improve the quality of recovery in patients with fast-induction anesthesia. ${ }^{15,16}$ Nonetheless, these drugs affect mental motor function, sleep patterns, hemodynamics, and pharmacokinetics, and the resulting problems have to be dealt with. For example, a small dose of midazolam can relieve the anxiety of fastinduction patients. However, if the ED95 of propofol is reduced by $41 \%$, it is necessary to administer midazolam $20 \mathrm{~min}$ in advance to obtain a satisfactory anesthetic effect without significant changes in the hemodynamics. ${ }^{12}$ If the dosage is increased, the awakening time will be extended by 3-6 hours or even longer. ${ }^{17}$ Moreover, midazolam can impair cognitive function, induce oversedation, and result in orientation disorders. ${ }^{18,19}$ Melatonin is a new medication that has sedative, hypnotic, analgesic, antiinflammatory, anti-oxidant, sleep-improving, and other effects, but its application in anesthesia and the dosage, timing, and pathways are yet to be studied. Hence, the drug is not an optimal choice for the anesthesiologist. Finding the appropriate medication remains to be a big challenge.

Ascorbic acid is a water-soluble antioxidant vitamin, which is known as vitamin C. It is a cofactor in several important enzymatic reactions and has neuroprotective and antioxidant effects. ${ }^{20,21}$ Vitamin $\mathrm{C}$ is commonly used to treat infections, cancers, autoimmune diseases, and diseases of unknown origin. ${ }^{22-24}$ It is safe even when injected in high dosages. ${ }^{25}$ Qiu et al reported that intraperitoneal injection of vitamin $\mathrm{C}$ reduced the dose of propofol by $37.5 \%$ in mice. ${ }^{26,27}$ However, it is unclear whether vitamin $\mathrm{C}$ can reduce the dosage and decrease the side effects of propofol in patients. We therefore conducted a trial to determine whether vitamin $\mathrm{C}$ reduces the dosage of propofol and decreases the incidence of hypotension during surgery.

\section{Materials and Methods}

We conducted a randomized, placebo-controlled trial at the Anesthesia and Surgery Center of the Chinese People's
Liberation Army General Hospital in Beijing, China. This study was conducted in accordance with the Helsinki Declaration and the research protocol was approved by the Medical Ethics Committee of the Chinese PLA General Hospital (S2016-026-03) and was registered in the Chinese Clinical Trial Registry, www.chictr.org.cn, number ChiCTR-TRC-16010112. All participants have signed informed consent forms in writing before the study. We have got all the consents obtained by the study participants prior to study commencement and data-access permission from participants.

We chose the patients aged $\geq 50$ years who were undergoing unilateral total knee arthroplasty (TKA) with total intravenous anesthesia combined with lumbar sciatic nerve block. The inclusion criteria were: patients satisfied the American Society of Anesthesiologists classification status I-III; BMI $\leq 30$. The exclusion criteria were: refusal to provide written informed consent; contraindications to nerve block (clotting disorders, puncture site infection); current severe psychiatric disease, alcoholism or drug dependence, sleep disorders, stroke or transient ischemic attack history; inability to communicate during the perioperative period; incomplete nerve block, additional analgesic or sedative medication needs during the intraoperative period.

A biostatistician independent of data management and statistical analysis used SAS 9.2 software (SAS Institute, Cary, NC) to generate random numbers (ratio 1:1). The results were sealed in sequentially numbered envelopes and kept at the study site until the end of the investigation. The patients were randomly divided into vitamin $\mathrm{C}(\mathrm{Vc})$ group or control group (normal saline). Vitamin $\mathrm{C}$ or normal saline was administered by a nurse anesthesiologist according to the randomization sequence. The anesthesiologists and the patients were masked to the treatment group during the entire study. The anesthesiologists could request unmasking of the treatment allocation in the event of an emergency (eg, patient's life endangered unexpectedly).

Non-invasive blood pressure, pulse oximetry, electrocardiograph, and bispectral index (BIS) were checked upon the patient's arrival to the operating room. Intravenous (IV) access was established. The Vc group was given vitamin C $0.067 \mathrm{~g} / \mathrm{kg}$ in a Murphy's dropper, and the control group was given an equivalent dose of normal saline. Sufentanil $5 \mu \mathrm{g}$ was administered to provide conscious sedation before nerve block insertion. The facemask was supplied with oxygen $(5 \mathrm{~L} / \mathrm{min})$. The patients were in the lateral decubitus position. After aseptic 
preparation, draping, and local infiltration, a 21-gauge 100-mm nerve block needle (Stimuplex $A^{\circledR}$, B Braun Melsungen AG, Tochigi-ken, Japan) was inserted under the guidance of a nerve stimulator. The peripheral nerve blocks were performed as previously reported by Liu. ${ }^{28}$ After the nerve stimulator was set at a frequency of $2 \mathrm{~Hz}$ and the current at $0.3-0.5 \mathrm{~mA}$ to determine the muscle response, negative aspiration was test. Subsequently, $30 \mathrm{~mL}$ of $0.4 \%$ ropivacaine for lumbar plexus block and $20 \mathrm{~mL}$ of $0.4 \%$ ropivacaine for sciatic nerve block were injected. After completion of the procedure, the sensory and motor blocks on the operated limb were evaluated every 5 minutes before proceeding with surgery until a satisfactory nerve block was achieved. If the patient continued to feel pain 30 minutes after the completion of the nerve block and the VAS score was greater than two, they were excluded from the study.

General anesthesia was given after the completion of the evaluation. A target-controlled infusion (TCI) of propofol (Diprivan 1\% AstraZeneca Corp) was administered using the Diprifusor, which relied on the Marsh pharmacokinetic model. The propofol infusion was started at 4 $\mu \mathrm{g} / \mathrm{mL}$ until the BIS declined to 60 . Rocuronium $0.6 \mathrm{mg} /$ $\mathrm{kg}$ and sufentanil $0.3 \mu \mathrm{g} / \mathrm{kg}$ (excluding $5 \mu \mathrm{g}$ sedation dose for nerve block) were intravenously administered, and a laryngeal mask airway (LMA) was inserted when the BIS declined to 60 . The parameters of mechanical ventilation were as follows: tidal volume $8 \sim 10 \mathrm{~mL} / \mathrm{kg}$, respiratory rate 12 times/minute, oxygen concentration $70 \% \sim 80 \%$, and $\mathrm{PetCO}_{2}$ 35 45 mmHg. Intravenous rocuronium $0.2 \mathrm{mg} / \mathrm{kg}$ was administered as needed. The total intravenous anesthesia of propofol was administrated during the operation. The BIS was controlled at $45 \sim 55$ by adjusting the concentration of propofol. An audible alarm was set when the BIS score went out of the prescribed range. During the maintenance of anesthesia, if the BIS value fell out of the predetermined range, the targeted blood concentration of propofol was either increased or decreased by $0.2 \mu \mathrm{g} / \mathrm{mL}$ until the BIS value returned to the targeted range. The total infusion dose of propofol (mg) was recorded during the operation, and the average maintenance dose $(\mathrm{mg} / \mathrm{kg} / \mathrm{h})$ was calculated. The arterial blood pressure was noted during the induction and maintenance periods. The time from the start of propofol infusion to the placement of LMA was defined as the induction period. The time from the insertion of LMA to the end of anesthesia was defined as the maintenance period. Hypotension was defined according to the following criteria: $^{8}$ 1. Preinduction: MAP $<70$ mmHg. 2. Postinduction: MAP decrease $>40 \%$ and $\mathrm{MAP}<70 \mathrm{mmHg}$ or MAP $<60 \mathrm{mmHg}$. Ephedrine hydrochloride $6 \mathrm{mg}$ was administered each time until the blood pressure returned to the preoperative baseline. The recovery time from the end of LMA to the time of discharge from the operating room was recorded.

All the patients received postoperative patientcontrolled intravenous analgesia (PCIA): sufentanil 150 $\mu \mathrm{g}$, ondansetron $16 \mathrm{mg}$, and normal saline $50 \mathrm{~mL}$, $0.5 \mathrm{~mL} / \mathrm{h}$ as background dose and $0.5 \mathrm{~mL}$ as bolus, with an 8-minute lockout time.

Power analysis showed that at a significance level of $5 \%$, the mean difference is 200 with a standard deviation of 200, at least 16 patients are needed in each group to achieve a power of $80 \%$. Statistical analyses were performed using SPSS Version 22.0 software. Demographic and clinical characteristics that were described as numbers (\%) and mean \pm standard deviation were compared using the $\chi^{2}$ test or the $t$-test. The data from non-normal distribution were represented as median (quartile interval) and analyzed using nonparametric test. All statistical tests were two-sided. $p<0.05$ was considered statistically significant.

\section{Results}

In total, 42 patients meet the inclusion and exclusion criteria between Jan 2017 and Jun 2017. Then they were randomly divided into two groups. Duration the operation, three patients change the original surgical plan, and the anesthesia method of three patients was changed because of an incomplete nerve block or the use of drugs affecting sedation (Figure 1). Finally, 36 patients were enrolled in the final data collection and have completion data. there were 15 patients in vitamin $\mathrm{C}$ group and 21 patients in control group. No unmasking occurred in the study. There were no significant differences in sex, age, weight, height, or BMI. Most patients belonged to Level II of ASA classification, and there were no significant differences in the incidence of comorbidities such as hypertension, coronary arterial disease, or diabetes between the control and Vc groups (Table 1).

In the anesthesia induction phase, there were no significant differences in the time of induction (control group: 3 minutes, range 2-4; Vc group: 3 minutes, range 2-3, p = 0.412 ), the induction dose of propofol (control group: $90 \mathrm{mg}$, range 80-115; Vc group: 100, range 90-110, $\mathrm{p}=$ 0.379 ), or the average induction dose (control group: $1.4 \pm$ 


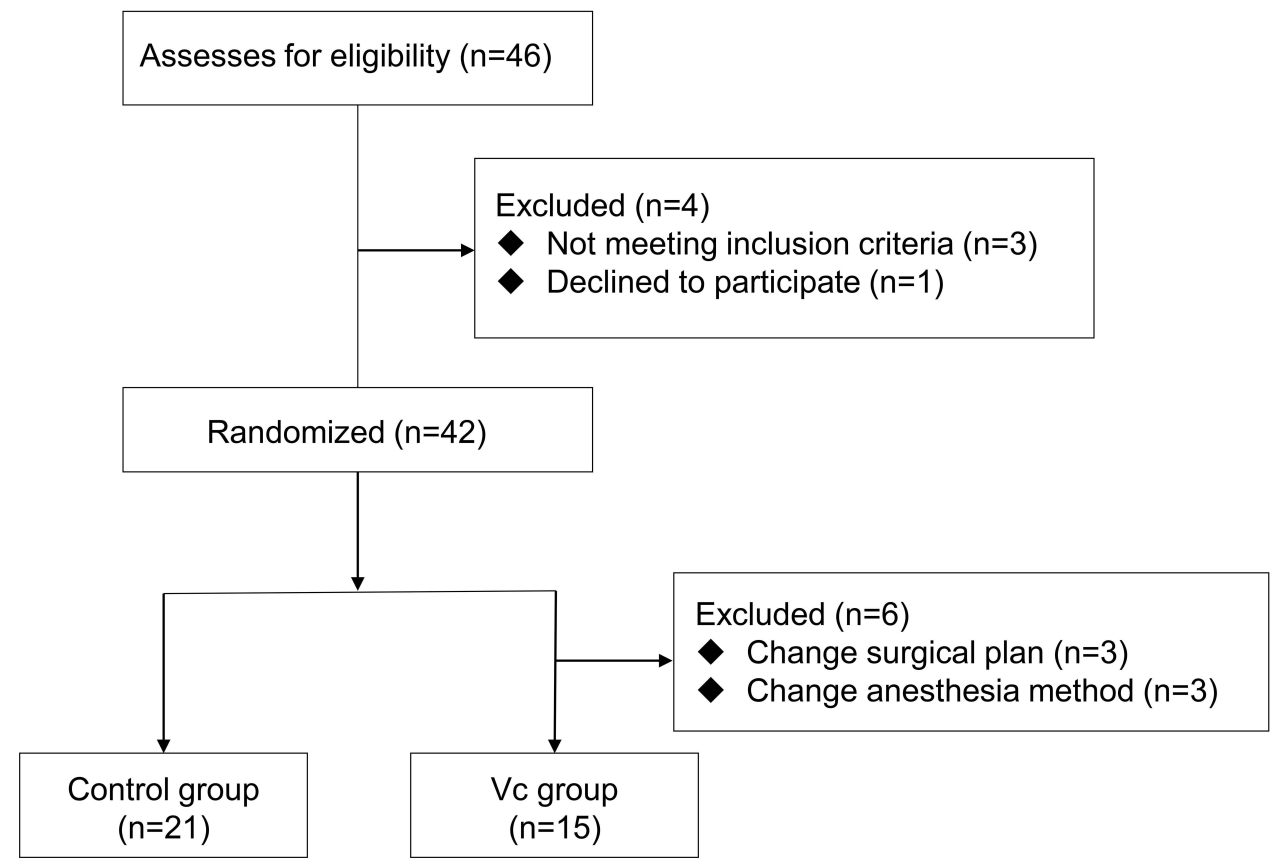

Figure I Flowchart of the trail.

$0.3 \mathrm{mg}$; Vc group: $1.5 \pm 0.4 \mathrm{mg} ; \mathrm{p}=0.637)$. In the anesthesia maintenance phase, there were no significant differences in the duration of anesthesia (control group: $118 \mathrm{~min}$, range 108.5-130; Vc group: $110 \mathrm{~min}$, range 96$124 ; \mathrm{p}=0.131$ ), but the total infusion dose of propofol was significantly lower in the Vc group than in the control group (Vc group: $704.3 \pm 188.6 \mathrm{mg}$; control group: $888.6 \pm 232.7 \mathrm{mg}$; percentage of change in Vc group/ control group: $20.7 \% ; \mathrm{p}=0.016$ ) and the average maintenance dose was also lower in the Vc group than in the control group (Vc group: $5.8 \pm 1.0 \mathrm{mg} / \mathrm{kg} / \mathrm{h}$; control group: $6.9 \pm 1.6 \mathrm{mg} / \mathrm{kg} / \mathrm{h} ; \mathrm{p}=0.013)$. However, there was no

Table I Patients' Demographic Characteristics

\begin{tabular}{|c|c|c|c|}
\hline Variables & Control Group $(n=2 I)$ & $\begin{array}{l}\text { Vc Group } \\
(n=15)\end{array}$ & $P$ \\
\hline Sex, male & I & 2 & \\
\hline Age, $y$, mean $\pm S D$ & $67.2 \pm 5.7$ & $69.1 \pm 7.4$ & 0.406 \\
\hline Weight, $\mathrm{Kg}$, mean $\pm \mathrm{SD}$ & $65.2 \pm 7.7$ & $66.7 \pm 7.4$ & 0.552 \\
\hline Height, $\mathrm{cm}$, mean $\pm \mathrm{SD}$ & $157.6 \pm 8.1$ & $161.8 \pm 6.2$ & 0.552 \\
\hline BMI, (IQR) & $26.8(24.8,28.3)$ & $26.8(23.4,27.3)$ & 0.328 \\
\hline Surgical side, R/L & $8 / 13$ & $7 / 8$ & \\
\hline \multicolumn{4}{|l|}{ ASA classification, n (\%) } \\
\hline 1 & $2(9.5)$ & I (6.7) & \\
\hline II & $17(81.0)$ & $13(86.6)$ & \\
\hline III & $2(9.5)$ & I (6.7) & \\
\hline \multicolumn{4}{|l|}{ Comorbidities } \\
\hline Hypertension, n (\%) & $9(42.9)$ & $5(33.3)$ & 0.563 \\
\hline $\begin{array}{l}\text { Coronary arterial disease, } \\
\mathrm{n}(\%)\end{array}$ & I (4.8) & $2(13.3)$ & 0.359 \\
\hline Diabetes n (\%) & $2(9.5)$ & $0(0)$ & 0.219 \\
\hline
\end{tabular}


Table 2 Intraoperative Clinical Data

\begin{tabular}{|c|c|c|c|}
\hline Variables & Control Group $(n=21)$ & Vc Group $(n=15)$ & $\boldsymbol{P}$ \\
\hline Time of induction, min, (IQR) & $3(2,4)$ & $3(2,4)$ & 0.412 \\
\hline Induction dose, mg, (IQR) & $90(80,115)$ & $100(90,110)$ & 0.379 \\
\hline Average induction dose, $\mathrm{mg} / \mathrm{kg} / \mathrm{h},(\mathrm{IQR})$ & $32(24.6,43.5)$ & $26.9(22.4,39.7)$ & 0.344 \\
\hline Average induction dose, $\mathrm{mg} / \mathrm{kg}$, mean $\pm \mathrm{SD}$ & $1.4 \pm 0.3$ & $1.5 \pm 0.4$ & 0.637 \\
\hline Duration of anesthesia, min, (IQR) & $118(108.5,130)$ & $110(96,124)$ & 0.131 \\
\hline Total infusion dose, $\mathrm{mg}$, mean $\pm \mathrm{SD}$ & $888.6 \pm 232.7$ & $704.3 \pm 188.6$ & 0.016 \\
\hline Average maintenance dose, $\mathrm{mg} / \mathrm{kg} / \mathrm{h}$, mean $\pm \mathrm{SD}$ & $6.9 \pm 1.6$ & $5.8 \pm 1.0$ & 0.013 \\
\hline Recover time, min, mean $\pm S D$ & $11.2 \pm 2.5$ & $12.8 \pm 2.7$ & 0.072 \\
\hline
\end{tabular}

significant difference in recover time (control group: 11.2 $\pm 2.5 \mathrm{mg}$; Vc group: $12.8 \pm 2.7 \mathrm{mg} ; \mathrm{p}=0.072$ ) (Table 2) between the two groups. Moreover, there were no significant differences in the hemodynamics, including the MAP during the intubation and 3,6, and 9 minutes after the intubation between the control and Vc groups. There was no significant difference in the incidence of intraoperative hypotension either (control group:76.2\%; Vc group: 60\%; $\mathrm{p}=0.465)$ (Table 3).

\section{Discussion}

The main finding of the current study was that intraoperative vitamin $\mathrm{C}$ can reduce the dosage of propofol in the TKA patients. In our study, we chose the patients who underwent unilateral TKA because the lumbar plexus combined with the sciatic nerve block can serve as an effective analgesic for the patients so that only propofol can be administered and the interference of other anesthetics could be avoided to the best possible extent. ${ }^{28}$ Our results were consistent with previous findings that antioxidants have synergistic effects on intravenous anesthetics. Qiu has reported the adjuvant effect of antioxidants on intravenous anesthetics in mice. ${ }^{26}$ When antioxidants were given, the total anesthetic dosage was significantly reduced or the time of anesthesia was prolonged. But there were no differences in the effects of hypnosis, antinociception, cardiovascular parameters, and body temperature in mice. These evidences indicated that the anesthetic effect has not been affected by the reduction in the use of propofol. Elas and Najafpour have also reported that vitamin $\mathrm{C}$ administration prior to ketamine treatment could be used to increase the duration of anesthesia in rabbits. ${ }^{29,30}$ Oral melatonin can enhance the anesthetic effect of thiopental and ketamine in rats. ${ }^{31}$ Egwu has stated that vitamin $\mathrm{C}$ prolonged the sleeping time of rabbits after xylazine administration. $^{32}$ The findings from the two aforementioned studies prove our conclusions indirectly, although these anesthetics and sedatives are rarely used clinically. Our result shows that there was no significant difference in the induction dose of propofol, which could be due to the fact that the induction time was too short for vitamin $\mathrm{C}$ to take effect.

In our results, there were no significant differences in the MAP and the incidence of hypotension during the intubation and maintenance periods between the control and Vc groups. One of the reasons for this observation could be that the TCI was started at $4.0 \mathrm{ug} / \mathrm{mL}$ in the intubation so that a high dose of propofol was administered within a short time, and the vitamin $\mathrm{C}$ had not yet taken effect. Moreover, a previous study has shown that propofol has a weak inhibitory effect on respiration and a strong inhibitory effect on circulation. ${ }^{33}$ In our study, to maintain BIS stably between 45 and 55 during the surgery, the required dose of propofol was high for the elderly

Table 3 Hemodynamics Data

\begin{tabular}{|l|c|c|c|}
\hline Variables & Control Group (n=2 I) & Vc Group (n= I5) & $\boldsymbol{P}$ \\
\hline Baseline MAP, mmHg, mean $\pm \mathrm{SD}$ & $97.6 \pm 6.9$ & $94.6 \pm 5.9$ & 0.185 \\
MAP in the intubation, $\mathrm{mmHg}, \mathrm{mean} \pm \mathrm{SD}$ & $81.9 \pm 7.3$ & $81.7 \pm 7.4$ & 0.940 \\
MAP after 3 minutes of intubation, $\mathrm{mmHg}$, mean $\pm \mathrm{SD}$ & $72.8 \pm 12.5$ & $73.6 \pm 11.5$ & 0.836 \\
MAP after 6 minutes of intubation, $\mathrm{mmHg}$, mean $\pm \mathrm{SD}$ & $72.2 \pm 11.1$ & $72.0 \pm 9.7$ & 0.944 \\
MAP after 9 minutes of intubation, $\mathrm{mmHg},(\mathrm{IQR})$ & $77.7(72.5,83.3)$ & $74.3(66.7,82.7)$ & 0.386 \\
Intraoperative hypotension, $\mathrm{n}(\%)$ & $16(76.2 \%)$ & $9(60 \%)$ & 0.465 \\
\hline
\end{tabular}


patients in both the groups even though vitamin $\mathrm{C}$ reduced the propofol dosage in the Vc group. Consistent with earlier reports, the increased prevalence of significant hypotension during the induction and maintenance periods is associated with higher doses of propofol. ${ }^{34,35}$

The mechanism of the synergistic effect of the antioxidants on intravenous anesthetics is unclear. Propofol is an intravenous anesthetic with both anesthetic and antioxidant properties. Its chemical structure contains a phenolic hydroxyl group. The compound is similar to $\alpha$-tocopherol and possesses proven in vitro and in vivo antioxidant properties. $^{36}$ Hans et al have established in different experimental models that propofol inhibits lipid peroxidation to protect cells from oxidative stress and improves the antioxidant capacity of plasma in humans. ${ }^{37,38}$ In addition, it has been reported that polyphenols serve as ligands for transcription factors, regulating protein kinase and protease activities. ${ }^{39-42}$ These antioxidant effects are similar to the effects of antioxidants in the body, such as vitamin C. Egwu has reported that vitamin $\mathrm{C}$ prolonged the sleeping time of rabbits after xylazine administration, these may be a result of the membrane stabilizing effect of vitamin $C$, thus preventing further movement of xylazine in and out of the brain. $^{32}$ Hence, we hypothesized the possibly mechanism of the synergistic effect of vitamin $\mathrm{C}$ on propofol is that pretreatment with vitamin $\mathrm{C}$ has effect of membrane stability and influence propofol induced anesthesia via modulatory effect on central nervous system functions or change the pharmacokinetic parameters of propofol in vivo and alters its elimination half-life. However, the mechanism of synergistic effect of the antioxidants on intravenous anesthetics will require to prove and the effect of $\mathrm{Vc}$ reduces the dosages of propofol on surgical patients such as postoperative pain, wound healing, prevention of chronic pain or reduction the incidence of postoperative cognitive dysfunction in elderly need further investigations.

\section{Limitations of the Study}

Our study has some limitations. First, the patients were limited to those from a single institution and undergoing unilateral TKA with total intravenous anesthesia combined with lumbar sciatic nerve block. Therefore, these results may not be generalizable to elderly surgical patients who undergo other surgeries in different settings. Second, we did not monitor the adverse reactions faced by patients receiving vitamin $\mathrm{C}$ although it has been reported ${ }^{26}$ that even large doses of vitamin $\mathrm{C}$ are well tolerated.

\section{Conclusion}

The findings from the present study suggest that antioxidant vitamin $\mathrm{C}$ can reduce the dose of propofol in the elderly undergoing unilateral TKA with total intravenous anesthesia combined with lumbar sciatic nerve block. The "cocktail combination" of antioxidants and anesthetics can achieve the desired sedative effect while simultaneously reducing the anesthetic dosage. Our founding may be provided a new method for clinically reducing the dosage of propofol.

\section{Data Sharing Statement}

The datasets generated and analysed in this study are not publicly available as the Ethics Committee has not approved the public availability of these data.

\section{Acknowledgments}

The author thanks all the participants. This study was supported by the Health Funding (15BJZ36, China) and National Key R\&D Program of China (2020YFC2008906).

\section{Author Contributions}

All authors made substantial contributions to conception and design, acquisition of data, or analysis and interpretation of data; took part in drafting the article or revising it critically for important intellectual content; agreed to submit to the current journal; gave final approval of the version to be published; and agree to be accountable for all aspects of the work.

\section{Disclosure}

Dr Weiguang Li reports a patent "A compound anesthetic drug issued to ZL 201310155624.6”. The authors report no conflicts of interest in this work.

\section{References}

1. Murphy PG, Myers DS, Davies MJ,et al. The antioxidant potential of propofol (2,6-diisopropylphenol). Br J Anaesth. 1992;68(6):613-618. doi: $10.1093 / \mathrm{bja} / 68.6 .613$

2. Hug CC, Mcleskey CH, Nahrwold ML, et al. Hemodynamic effects of propofol: data from over 25,000 patients. Anesth Analg. 1993;77 (4Suppl):S21-S29. doi:10.1213/00000539-199310000-00054

3. Sebel PS, Lowdon JD. Propofol: a new intravenous anesthetic. Anesthesiology. 1989;71(2):260-277. doi:10.1097/00000542198908000-00015

4. Grounds RM, Morgan M, Lumley J. Some studies on the properties of the intravenous anaesthetic, propofol ('Diprivan') - a review. Postgrad Med J. 1985;61:90-95. doi:10.1186/1687-1499-2013-257

5. Kaplan JA, Guffin AV, Mikula S, et al. Comparative hemodynamic effects of propofol and thiamylal sodium during anesthetic induction for myocardial revascularization. J Cardiothorac Anesth. 1988;2 (3):297-302. doi:10.1016/0888-6296(88)90308-0

6. Butterworth JF. Morgan \& Mikhail's Clinical anesthesiology. Mcgraw Hill; 2013. 
7. Mccollum JSC, Dundee JW. Comparison of induction characteristics of four intravenous anaesthetic agents. Anaesthesia. 1986;41 (10):995-1000. doi:10.1111/j.1365-2044.1986.tb12740.x

8. Reich D, Hossain S, Krol M. Predictors of hypotension after induction of general anesthesia. Anesth Analg. 2005;101(3):622-628. doi:10.1213/01.ANE.0000175214.38450.91

9. Farhan M, Hoda MQ, Ullah H. Prevention of hypotension associated with the induction dose of propofol: a randomized controlled trial comparing equipotent doses of phenylephrine and ephedrine. J Clin Pharmacol. 2015;31(4):526-530. doi:10.4103/0970-9185.169083

10. Klare P, Huth R, Haller B, et al. Patient position and hypoxemia during propofol sedation for colonoscopy: a randomized trial. Endoscopy. 2015;47(12):1159-1166. doi:10.1055/s-0034-1392329

11. Krzisch M, Sultan S, Sandell J, et al. Propofol anesthesia impairs the maturation and survival of adult-born hippocampal neurons. Anesthesiology. 2013;118(3):602-610. doi:10.1097/ ALN.0b013e3182815948

12. Wilder-Smith OH, Ravussin PA, Decosterd LA, et al. Midazolam premedication reduces propofol dose requirements for multiple anesthetic endpoints. Can J Anesth. 2001;48(5):439-445. doi:10.1007/ BF03028305

13. Wilder-Smith O, Ravussin PA, Decosterd LA, et al. Midazolam premedication and thiopental induction of anaesthesia: interactions at multiple end-points. $B r \quad J$ Anaesth. 1999;83(4):590-595. doi:10.1093/bja/83.4.590

14. Altan A, Turgut N, Yldz F, et al. Effects of magnesium sulphate and clonidine on propofol consumption, haemodynamics and postoperative recovery. Br J Anaesth. 2005;94(4):438-441. doi:10.1093/bja/ aei070

15. White PF, Kehlet H, Neal JM, et al. The role of the anesthesiologist in fast-track surgery: from multimodal analgesia to perioperative medical care. Anesth Analg. 2007;104(6):1380-1396. doi:10.1213/ 01.ane.0000263034.96885.e1

16. Yousaf F, Seet E, Venkatraghavan L, et al. Efficacy and safety of melatonin as an anxiolytic and analgesic in the perioperative period: a qualitative systematic review of randomized trials. Anesthesiology. 2010;113(4):968-976. doi:10.1097/ALN.0b013e3181e7d626

17. Rex DK. Review article: moderate sedation for endoscopy: sedation regimens for non-anaesthesiologists. Aliment Pharmacol Ther 2006;24(2):163-171. doi:10.1111/j.1365-2036.2006.02986.x

18. Covey-Crump GL, Murison PJ. Fentanyl or midazolam for co-induction of anaesthesia with propofol in dogs. Vet Anaesth Analg. 2010;35(2):463-472. doi:10.1111/j.1467-2995.2008.00408.x

19. Wittenborn JR. Effects of benzodiazepines on psychomotor performance. $\mathrm{Br} J$ Anaesth. 2012;7(S1):61S-67S. doi:10.1111/ j.1467-2995.2008.00408.x

20. Rebec GV, Pierce RC. A vitamin as neuromodulator: ascorbate release into the extracellular fluid of the brain regulates dopaminergic and glutamatergic transmission. Prog Neuribiol. 1994;43 (6):537-565. doi:10.1016/0301-0082(94)90052-3

21. Rice ME. Ascorbate regulation and its neuroprotective role in the brain. Trends Neurosci. 2000;23(5):209-216. doi:10.1016/S01662236(99)01543-X

22. Riordan NH, Riordan HD, Casciari JP. Clinical and experimental experiences with intravenous vitamin C. J Orthomol Med. 2000;15 (4):201-213.

23. Goodman S. Vitamin C, Infectious Diseases, \& Toxins - Curing the Incurable. Positive Health; 2003.

24. González MJ, Miranda-Massari JR, Mora EM, et al. Orthomolecular oncology review: ascorbic acid and cancer 25 years later. Integr Cancer Ther. 2005;4(1):32-44. doi:10.1177/1534735404273861
25. Padayatty SJ, Sun AY, Chen Q, et al. Vitamin C: intravenous use by complementary and alternative medicine practitioners and adverse effects. PLoS One. 2010;5(7):e11414. doi:10.1371/journal.pone.0011414

26. Qiu H. Adjuvant Effect of Antioxidants on Propofol or Etomidate Anesthesia in Mice. Peking Union Medical College; 2012.

27. Mengzhuo G, Weiguang L, Liu X, et al. Anesthetic effects of repeated dosing with propofol and vitamin C in mice. J South Med Univ. 2015;35(12):1701-1704. doi:10.3969/j.issn.16734254.2015.12.07

28. Liu JL, Hong Z, Yuan WX, et al. Peripheral nerve blocks versus general anesthesia for total knee replacement in elderly patients on the postoperative quality of recovery. Clin Interv Aging. 2014;9:341-350. doi:10.2147/CIA.S56116

29. Elsa A, Ubandawaki S. Ketamine anaesthesia following premedication of rabbits with vitamin C. J Vet Sci. 2005;6(3):239-241. doi:10.4142/jvs.2005.6.3.239

30. Hasar RH, Najafpour A. Effects of ascorbic acid for premedication of cats following ketamine anaesthesia. J Anim Vet Adv. 2009;8 (11):2196-2199. doi:10.1016/j.fsi.2009.10.007

31. Budhiraja S, Singh J. Adjuvant effect of melatonin on anesthesia induced by thiopental sodium, ketamine, and ether in rats. Methods Find Exp Clin Pharmacol. 2005;27(10):697-699. doi:10.1358/ mf.2005.27.10.948896

32. Egwu GO, Mshelia GD, Sanni S, et al. The effect of vitamin C at varying times on physiological parameters in rabbits after xylazine anaesthesia. Vet Ital. 2011;47(1):97-104. doi:10.3906/vet-1102-784

33. Yamagata T, Hirasawa D, Fujita N, et al. Efficacy of propofol sedation for endoscopic submucosal dissection (ESD): assessment with prospective data collection. Intern Med. 2011;50(14):1455-1460. doi:10.2169/internalmedicine.50.4627

34. Dundee JW, Robinson FP, Mccollum JSC, et al. Sensitivity to propofol in the elderly. Anaesthesia. 1986;41(5):482-485. doi:10.1111/ j.1365-2044.1986.tb13271.x

35. Phillips AT, Deiner S, Lin HM, et al. Propofol use in the elderly population: prevalence of overdose and association with 30-day mortality. Clin Ther. 2015;37(12):2676-2685. doi:10.1016/j. clinthera.2015.10.005

36. Li W, Yu Z, Liu Y, et al. In vitro kinetic evaluation of the free radical scavenging ability of propofol. Anesthesiology. 2012;116 (6):1258-1266. doi:10.1097/ALN.0b013e3182567dcc

37. Hans P, Deby-Dupont G, Deby C, et al. Increase in antioxidant capacity of plasma during propofol anesthesia. J Neurosurg Anesth. 1997;9(3):234-236. doi:10.1097/00008506-199707000-00006

38. Sagara Y, Hendler S, Khoh-Reiter S, et al. Propofol hemisuccinate protects neuronal cells from oxidative injury. J Neurochem. 2010;73 (6):2524-2530. doi:10.1046/j.1471-4159.1999.0732524.x

39. Amakura Y, Tsutsumi T, Nakamura M, et al. Activation of the aryl hydrocarbon receptor by some vegetable constituents determined using in vitro reporter gene assay. Biol Pharm Bull. 2003;26 (4):532-539. doi:10.1248/bpb.26.532

40. Agarwal R. Cell signaling and regulators of cell cycle as molecular targets for prostate cancer prevention by dietary agents. Biochem Pharmacol. 2000;60(8):1051-1059. doi:10.1016/s0006-2952(00) 00385-3

41. Moon SK, Cho GO, Jung SY, et al. Quercetin exerts multiple inhibitory effects on vascular smooth muscle cells: role of ERK1/2, cell-cycle regulation, and matrix metalloproteinase-9. Biochem Biophys Res. 2003;301(4):1069-1078. doi:10.1016/s0006-291x(03) 00091-3

42. Yang LQ, Yu WF, Cao YF,et al. Potential inhibition of cytochrome P450 3A4 by propofol in human primary hepatocytes. World J Gastroenterol. 2003;9(9):1959-1962. doi:10.3748/wjg.v9.i9.1959 


\section{Publish your work in this journal}

The Journal of Pain Research is an international, peer reviewed, open access, online journal that welcomes laboratory and clinical findings in the fields of pain research and the prevention and management of pain. Original research, reviews, symposium reports, hypothesis formation and commentaries are all considered for publication. The manuscript management system is completely online and includes a very quick and fair peer-review system, which is all easy to use. Visit http:// www.dovepress.com/testimonials.php to read real quotes from published authors.

Submit your manuscript here: https://www.dovepress.com/journal-of-pain-research-journal 